\title{
Diabetes: How Are We Diagnosing and Initially Managing It?
}

\author{
Patrick J. O'Connor, MD, MPH \\ Edward Gregg, $P b D^{2}$ \\ William A. Rush, PbD ${ }^{1}$ \\ Linda M. Cherney, RD, MPH \\ Michael N. Stiffman, MD, MSPH ${ }^{1}$ \\ Michael M. Engelgau, MD, MPH² \\ ${ }^{1}$ HealthPartners Research Foundation, \\ Minneapolis, Minn \\ ${ }^{2}$ Centers for Disease Control and Prevention, \\ Atlanta, Ga
}

\begin{abstract}
PURPOSE We undertook this study to examine the symptoms, clinical events, and types of health care encounters that preceded the diagnosis of diabetes mellitus in adults, and to examine changes in glycemic control and cardiovascular risk factors in the first year after a diabetes diagnosis.
\end{abstract}

METHODS We conducted a historical cohort study of patients in a large multispecialty medical group in Minnesota. Among 55,121 adults who were continuously enrolled in the health plan and receiving care at the study medical group from January 1, 1993, to December 31, 1996, we identified 504 who received a new diagnosis of diabetes in 1995 or 1996. Our main outcome measures were the type of symptoms at diagnosis; the clinical circumstances and type of encounter that led to diabetes diagnosis; and changes in glycemic control (assessed by hemoglobin $A_{1 c}\left[\mathrm{HbA}_{1 c}\right]$ value), low-density lipoprotein cholesterol level, blood pressure (BP), aspirin use, and body weight in the first year after diagnosis, ascertained from a detailed review of medical records.

RESULTS Almost one third (32.3\%) of adults with newly diagnosed diabetes had symptoms of hyperglycemia at initial diagnosis. Compared with patients who did not have hyperglycemia symptoms at diagnosis, those who did were younger and more often male, and had lower comorbidity scores and higher $\mathrm{HbA}_{1 \mathrm{c}}$ values $(9.9 \%$ vs $8.1 \%)$ at diagnosis ( $P<.01$ for each comparison). In the 12 months after diagnosis, the group as a whole had significant improvements $(P<.001)$ in $\mathrm{HbA}_{1 c}$ values (from $8.8 \%$ to $7.1 \%$ ), systolic blood pressure (137.5 to $133.2 \mathrm{~mm} \mathrm{Hg}$ ), diastolic blood pressure (80.7 to $77.3 \mathrm{~mm} \mathrm{Hg}$ ), weight (207.7 to $201.1 \mathrm{lb})$, and aspirin use (15.3\% to $26.1 \%)$. Improvements were seen in all patient subgroups, including those defined by symptoms at diagnosis and by visit type at diagnosis.

CONCLUSIONS Primary care practices may improve detection of undiagnosed diabetes in primary care and improve 1-year outcomes by being vigilant for symptoms of diabetes, by evaluating those at high risk for this disorder, and by instituting appropriate treatments at the time of diagnosis.

Ann Fam Med 2006;4:15-22. DOI: 10.1370/afm.419.

\section{INTRODUCTION}

7 he prevalence of diabetes has increased rapidly during the past several decades and is expected to continue to rise. ${ }^{1-4}$ A consistent finding of this growing epidemic has been that $35 \%$ to $50 \%$ of cases of diabetes are undiagnosed. There may be some benefit in detecting and treating symptomatic and screening for and treating asymptomatic undiagnosed diabetes. ${ }^{5-10}$ Whether this would be best accomplished through more aggressive case finding in symptomatic persons or through opportunistic screening of asymptomatic persons is unclear, however. Several quantitative and qualitative studies suggest that a high proportion of patients have diabetes symptoms before diagnosis and that there is considerable heterogeneity in clinical and diagnostic processes that lead to a diabetes diagnosis. ${ }^{11-16}$ The persistent finding that many patients are symptomatic for long periods before diabetes diagnosis signals the need to improve clinical pro- 
cesses and case finding. On the other hand, the proportion of patients who are truly asymptomatic at the time of diagnosis could be used as an indicator of adequacy of diabetes screening and identification procedures; the higher this proportion is, the better patient and physician awareness of diabetes may be. ${ }^{17}$

Currently, the short-term impact of diabetes diagnosis on control of risk factors for macrovascular or microvascular complications is not completely understood. ${ }^{6,18}$ Because more than $70 \%$ of adults older than age 40 receiving a diagnosis of type 2 diabetes eventually die of cardiovascular or cerebrovascular disease, ${ }^{19}$ a particularly important question is whether diabetes diagnosis leads to improved control of cardiovascular risk factors. Such a finding would support the need for more aggressive efforts to improve the diagnosis of diabetes in primary care.

This study was designed to determine how diabetes is diagnosed and initially managed in primary care. We identified the types of clinical encounters, symptoms, and laboratory tests that led to initial diabetes diagnosis, and measured changes in risk factors for microvascular and macrovascular complications in the 12 -month period after a new diagnosis.

\section{METHODS}

\section{Study Design and Study Site}

This historical cohort study was conducted in the HealthPartners Medical Group (HPMG), a Minnesota multispecialty medical group that, in 1996, had 175,000 prepaid enrolled adults receiving primary care from about 130 internists and family physicians at 19 clinics in the Twin Cities metropolitan area. Enrolled patients had a single outpatient medical record kept at their primary care clinic that included all their outpatient clinical data. ${ }^{20}$

\section{Study Patients}

Adults with an initial diagnosis of diabetes made in 1995 or 1996 were identified through a 3-step process. In the first step, all adults who were continuously enrolled and who received 1 or more inpatient or outpatient diabetes diagnosis codes (International Classification of Diseases, Ninth Revision [ICD-9] codes 250.xx) from January 1, 1993, to December 31, 1996, were identified as potential study patients.

In the second step, those who met previously validated criteria for diagnosis of diabetes from January 1, 1993, to December 31, 1994, were identified and excluded. This diabetes identification method required either (1) 1 inpatient or 2 outpatient diabetes-specific ICD-9 codes (250.xx) or (2) filled prescriptions for 1 or more diabetes-specific drugs (insulin or sulfonylureas) in calendar year 1993 or 1994. This method of diabetes identification has been validated and has an estimated sensitivity of 0.91 , specificity of 0.99 , and positive predictive value of $0.94 .{ }^{21}$

In the third step, chart audits were performed for remaining patients to confirm a new diabetes diagnosis between January 1, 1995, and December 31, 1996. Confirmation required documentation of either (1) first use of any diabetes-specific drug (insulins, sulfonylureas, or biguanides) or (2) laboratory test results that established a diabetes diagnosis based on national diagnostic criteria in effect from 1993 to 1996: initial and confirmatory fasting plasma glucose concentrations of greater than $140 \mathrm{mg} / \mathrm{dL}$, or a random plasma glucose concentration of greater than $200 \mathrm{mg} / \mathrm{dL}$ with symptoms, or a 2-hour plasma glucose value of greater than $200 \mathrm{mg} / \mathrm{dL}$ on a 2-hour, 75 -g glucose tolerance test. ${ }^{22}$ All available data for these patients from before January 1, 1995, were also evaluated, and patients who met these criteria for diabetes diagnosis before that date were excluded.

\section{Definition of Variables and Data Collection}

\section{Data Obtained From Electronic Databases}

Administrative and clinical databases were used to obtain data on age; sex; all ICD-9 diagnoses related to diabetes from January 1, 1993, to December 31, 1996; filled prescriptions during the study period; and laboratory test dates and results for glycated hemoglobin $\left(\mathrm{HbA}_{\mathrm{Ic}}\right)$, serum glucose, and oral glucose tolerance tests.

All laboratory tests included in the analysis were performed at a single centralized, accredited clinical chemistry laboratory. There were no changes in laboratory assays or procedures for $\mathrm{HbA}_{1 \mathrm{c}}$ or cholesterol tests during the study period. Tests for $\mathrm{HbA}_{1 \mathrm{c}}$ were performed using a standard liquid chromatographic method on an analyzer (Variant Hemoglobin Testing System, Bio-Rad Laboratories, Hercules, Calif) with a normal range of $4.5 \%$ to $6.1 \%$, and a coefficient of variation of $0.58 \%$ at an $\mathrm{HbA}_{1 \mathrm{c}}$ value of $8.8 \% .{ }^{23}$ Data on finger-stick glucose values obtained in the office by nurses were abstracted during the chart audit because these data were not included in electronic databases.

A modified Charlson Comorbidity Index was assigned to each study patient based on a standard set of diagnostic codes assigned over the 12-month period before the date of first diabetes diagnosis. ${ }^{24-26}$

\section{Data Obtained From Medical Record Reviews}

Medical records were reviewed to identify the specific date of initial diabetes diagnosis based on laboratory results. For each patient, this date was used to define 1 -year periods before and after the diagnosis. Weight, aspirin use, and blood pressure values were recorded for the 3 -month period before the diagnosis and the period 
from 9 to 15 months after diagnosis to ascertain change in these measures with time.

Two trained research nurses reviewed medical records. Initial training included instruction based on written chart audit rules; it was followed by joint review of records by the 2 nurses, the project coordinator (LMC), and a physician (PJO) until this group reached consensus on all audit data on 10 consecutive charts. Subsequent agreement between nurses was evaluated on randomly selected charts that were audited twice and was found to exceed $95 \%$.

Among study patients, the proportion with sufficient data to assess change in risk factors was $66.0 \%$ for $\mathrm{HbA}_{1 \mathrm{c}}, 86.9 \%$ for blood pressure, $100 \%$ for aspirin use, and $87.7 \%$ for weight. Changes in lipid control are described below, but multivariate analysis of change in this measure is not reported because of missing data.

\section{Categorization of Circumstances Leading} to Diabetes Diagnosis

The research nurses used pretested audit forms to cat egorize medical encounters related to a new diabetes diagnosis in 2 independent dimensions: visit type and patient symptoms

Visit type was assigned to 1 of 4 mutually exclusive categories: (1) preventive care (a planned visit for an annual physical examination, Papanicolaou test, etc), (2) preoperative or procedure related (a planned visit to obtain clearance for surgery or a procedure), (3) chronic ongoing condition (eg, a planned visit for asthma, heart disease, depression, hypertension), or (4) acute medical problem (eg, a visit for acute upper respiratory tract infection, pain, or cellulitis).

Patient symptoms at a particular visit were classified into 1 or more of 4 mutually exclusive categories: (1) symptoms related to hyperglycemia (polyuria, polydipsia, polyphagia, weight loss, fatigue, acute blurry vision), (2) symptoms related to long-term complications of diabetes (leg or foot pain, carpal tunnel syndrome, visual deterioration other than acute blurry vision, cataracts), (3) symptoms unrelated to diabetes, or (4) no symptoms.

\section{Statistical Analysis}

The $\chi^{2}$ statistic and $t$ tests were used to describe differences in the characteristics of various groups of patients. Multivariate modeling of the data was performed using logistic or general linear models to ascertain the relationship of sex, age, comorbidity index, and other independent variables to the main dependent variables: (1) symptom group $;$ (2) change in risk factor status in the 12 months after diagnosis, (3) whether patients reached evidence-based goals for $\mathrm{HbA}_{1 \mathrm{c}}$, blood pressure, or aspirin use within 12 months after diag- nosis; and (4) type of test used to establish a diagnosis of diabetes. Multivariate models were developed using standard SAS procedures. ${ }^{27}$

\section{Human Subjects Protection}

The study protocol was reviewed, approved in advance, and monitored by the institutional review boards of HealthPartners and the Centers for Disease Control and Prevention.

\section{RESULTS}

\section{Identification and Characteristics of Adults With Newly Diagnosed Diabetes}

The algorithm used to identify study patients with newly diagnosed diabetes is shown in Figure 1. A total of $504(94.6 \%)$ of 533 study patients had sufficient data to classify the types of visits and types of symptoms that led to their initial diabetes diagnosis and are the basis of this report. Characteristics of these patients are shown in Table 1. Not shown in the table are the baseline Charlson Comorbidity Indexes (mean = 0.79), and mean low-density lipoprotein (LDL) cholesterol value of $133 \mathrm{mg} / \mathrm{dL}$, available for only 200 patients (39\%). Only 136 (68\%) of these 200 individuals had a follow-up LDL-cholesterol measurement within the study period $($ mean $=129 \mathrm{mg} / \mathrm{dL})$; therefore, no further analysis of LDL-cholesterol data is presented.

\section{Type of Symptoms at the Time of Diagnosis}

At diagnosis, 32.3\% of the 504 patients had symptoms of hyperglycemia, $7 \%$ had symptoms of chronic complications of diabetes, and $61 \%$ did not have any diabetesrelated symptoms (ie, they had other or no symptoms). Those with symptoms of hyperglycemia were younger $(P=.004)$, were more likely to be male $(P=.002)$, and had lower comorbidity indexes $(P<.001)$ and higher $\mathrm{HbA}_{1 \mathrm{c}}$ values at diagnosis $(9.9 \%$ vs $8.1 \%, P=.01)$ than patients who had no symptoms of hyperglycemia.

\section{Type of Visit Leading to Diabetes Diagnosis}

About one half of the new diagnoses were made at planned visits, including preventive care visits (21.2\%), routine preoperative assessments $(5.7 \%)$, and chronic disease visits $(20.8 \%)$. Acute care visits led to diabetes diagnosis in $42.8 \%$ of patients. Those receiving the diagnosis at acute care visits had higher mean $\mathrm{HbA}_{1 \mathrm{c}}$ values at the time of diagnosis than those receiving the diagnosis at scheduled visits $(9.4 \%$ vs $8.2 \%, P<.001)$. Cross-classification by symptoms and by type of visit showed that patients who had hyperglycemia symptoms were more likely than expected to have diabetes diagnosed at acute care visits. Conversely, patients receiving a diagnosis but not having any hyperglycemia 
symptoms obtained their diagnosis through preventive or chronic disease care visits.

\section{Type of Tests Used to Diagnose Diabetes}

The $\mathrm{HbA}_{1 \mathrm{c}}$ test was the most frequently used diagnostic test $(79 \%)$, followed by the fasting glucose test $(47 \%)$, the 2 -hour glucose tolerance test (38\%), and the random glucose test (31\%) (Figure 2). A mean of 1.9 glycemia-related tests were done per patient dur- ing the 3-month period before the date of diabetes diagnosis.

The percentage of patients with random glucose tests at the time of diagnosis was greater among those with hyperglycemia symptoms than among those without them. Use of other tests near the time of diagnosis did not vary significantly across type of diagnostic visit or type of symptoms at diagnosis. It seems likely that some $\mathrm{HbA}_{1 \mathrm{c}}$ tests were done for early assessment of glycemic

\section{Figure 1. Algorithm for identifying incident cases of diabetes using automated database and medical record review.}

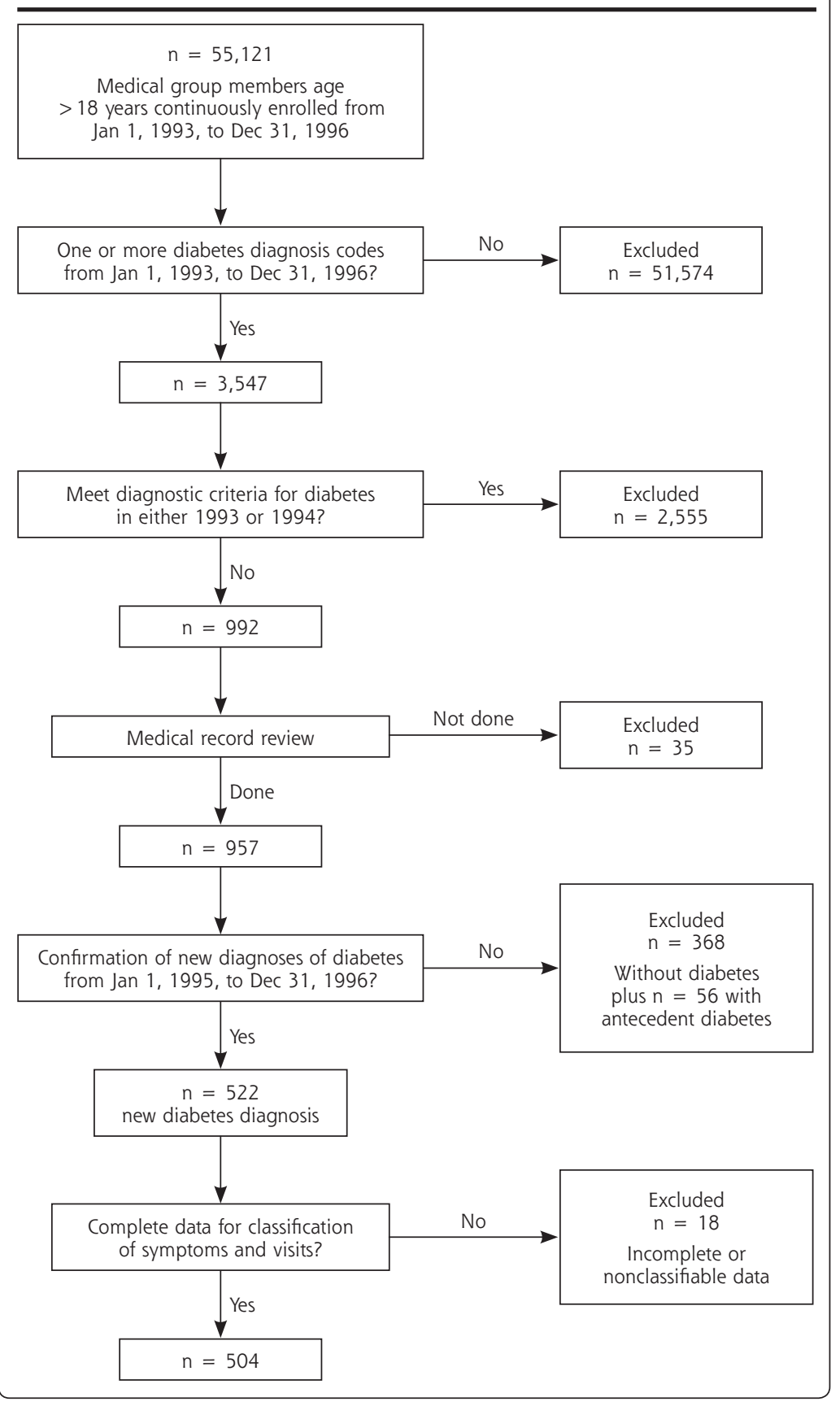

control status, rather than for diagnosis; however, interviews with physicians in this medical group indicate that many view the $\mathrm{HbA}_{1 \mathrm{c}}$ test as an adequate diagnostic test for diabetes.

\section{Changes in Risk Factors in the Year After Diagnosis}

In the year after diagnosis, the overall mean $\mathrm{HbA}_{1 \mathrm{c}}$ value fell from $8.8 \%$ to $7.1 \%(P<.001)$. Mean weight decreased from 207.7 to $201.1 \mathrm{lb}$ $(P<.001)$. Significant improvements were also seen in systolic blood pressure (137.5 to $133.2 \mathrm{~mm} \mathrm{Hg}, P$ $<.001)$, diastolic blood pressure (80.7 to $77.3 \mathrm{~mm} \mathrm{Hg}, P<.001)$, and aspirin use (from $15.3 \%$ to $26.1 \%, P<.001$ ). Those with diabetes symptoms at diagnosis had greater improvement in $\mathrm{HbA}_{1 \mathrm{c}}$ (an absolute reduction of $2.8 \%)$, but this difference became nonsignificant when baseline $\mathrm{HbA}_{1 \mathrm{c}}$ value was entered in the model.

Multivariate models were constructed to adjust observed changes in clinical measures from baseline to the 12-month follow-up for differences in patient age, sex, comorbidity, and baseline clinical measures. These models showed that older age was associated with greater 1 -year improvements in systolic blood pressure $(\mathrm{F}=4.35, \mathrm{P}$ $<.04)$ and diastolic blood pressure $(\mathrm{F}$ $=5.79, P<.02)$ and that systolic blood pressure improved significantly more in men than in women $(\mathrm{F}=4.59, \mathrm{P}$ $<.04$ ) (results not shown). Change in $\mathrm{HbA}_{1 \mathrm{c}}$ was not significantly related to age, sex, or baseline comorbidity.

A total of $42 \%$ of study patients were treated with insulin $(5 \%)$, oral hypoglycemic agents (39\%), or both (2\%) within 12 months of initial diabetes diagnosis. 
Table 1. Clinical Parameters at Baseline and 12-Month Follow-Up for Adults With Newly Diagnosed Diabetes, by Type of Symptoms at Diagnosis

\begin{tabular}{|c|c|c|c|c|c|c|c|c|c|c|}
\hline \multirow[b]{3}{*}{ Parameter } & \multirow{2}{*}{\multicolumn{2}{|c|}{$\begin{array}{l}\text { Baseline } \\
(\mathrm{N}=504)\end{array}$}} & \multirow{2}{*}{\multicolumn{2}{|c|}{$\begin{array}{l}\text { Follow-up } \\
(N=504)\end{array}$}} & \multicolumn{6}{|c|}{ Follow-up, by Type of Symptoms at Diagnosis } \\
\hline & & & & & \multicolumn{2}{|c|}{$\begin{array}{l}\text { Hyperglycemia } \\
(\mathrm{n}=163)\end{array}$} & \multicolumn{2}{|c|}{$\begin{array}{l}\text { Unrelated } \\
(n=96)\end{array}$} & \multicolumn{2}{|c|}{$\begin{array}{c}\text { None } \\
(n=207)\end{array}$} \\
\hline & No.* & Baseline & No. ${ }^{+}$ & Change & No. ${ }^{+}$ & Change & No. ${ }^{\dagger}$ & Change & No. ${ }^{\dagger}$ & Change \\
\hline Weight, Ib & 452 & 207.7 & 442 & $-6.6^{\ddagger}$ & 133 & $-6.7^{\ddagger}$ & 85 & $-63.8^{\ddagger}$ & 184 & $-6.5^{\ddagger}$ \\
\hline $\mathrm{HbA}_{1 c,} \%$ & 452 & 8.8 & 452 & $-1.7^{\ddagger}$ & 102 & $-2.8^{\ddagger}$ & 62 & $-1.1^{\ddagger}$ & 138 & $-1.2^{\ddagger}$ \\
\hline $\mathrm{SBP}, \mathrm{mm} \mathrm{Hg}$ & 471 & 137.5 & 439 & $-4.3^{\ddagger}$ & 132 & $-3.5^{\S}$ & 87 & -2.5 & 181 & $-6.2^{\ddagger}$ \\
\hline DBP, mm Hg & 471 & 80.7 & 438 & $-3.4^{\ddagger}$ & 132 & $-3.9^{\ddagger}$ & 86 & -3.0 & 181 & $-3.9^{\ddagger}$ \\
\hline Aspirin use, \% & 504 & 15.3 & 504 & $+10.8^{\ddagger}$ & 163 & $+6.8^{\S}$ & 96 & $+17.7^{\S}$ & 207 & $+11.6^{\S}$ \\
\hline LDL-cholesterol, mg/dL & 200 & 133.4 & 136 & $-4.8^{\S}$ & 41 & -5.6 & 26 & -2.7 & 55 & -6.2 \\
\hline \multicolumn{11}{|c|}{$\mathrm{HbA}_{1 \mathrm{C}}=$ hemoglobin $\mathrm{A}_{1 \mathrm{c}}$ S SBP = systolic blood pressure; DBP = diastolic blood pressure; $\mathrm{LDL}=$ low-density lipoprotein. } \\
\hline \multicolumn{11}{|c|}{$\begin{array}{l}\text { * Number of patients with baseline value for the designated measure. } \\
\text { † Number of patients with both baseline and follow-up values for the designated measure. } \\
\text { † } P<.01 \text {. } \\
\text { § } P<.5 \text {. }\end{array}$} \\
\hline
\end{tabular}

The proportion of patients who achieved clinical goals recommended at the time (based on local and national guidelines ${ }^{28}$ ) of diagnosis and 1 year later are shown in Figure 3. The largest improvement was in $\mathrm{HbA}_{1 \mathrm{c}}$, for which the percentage of patients with a value less than $7 \%$ doubled from $29 \%$ to $58 \%$. Less substantial gains in aspirin use and blood pressure control were also observed.

\section{DISCUSSION}

Few studies have systematically examined the clinical circumstances that lead to diabetes diagnosis and subsequent changes in care in primary care. Two of our key findings may have important implications for detecting and screening for diabetes in primary care: (1) 39\% of patients with undiagnosed diabetes had diabetes-related symptoms at the time of detection, and $43 \%$ received their diagnosis at visits for acute care; and (2) clinically significant improvements in $\mathrm{HbA}_{1 \mathrm{c}}$ levels, systolic and diastolic blood pressures, aspirin use, and weight occurred within 1 year of a new diagnosis of diabetes.

The first of these findings suggests that improved awareness of symptoms on the part of patients and their clinicians may have a substantial yield $i$ the second finding is of great interest because the improvements were large enough to decrease substantially the risk of diabetes complications if maintained over time. In the UK Prospective Diabetes Study (UKPDS), each 1\% decrease in $\mathrm{HbA}_{1 \mathrm{c}}$ value yielded about a $30 \%$ reduction in incidence of microvascular complications plus
Figure 2. Percentage of patients $(n=504)$ who had the following tests at the time of diabetes diagnosis.

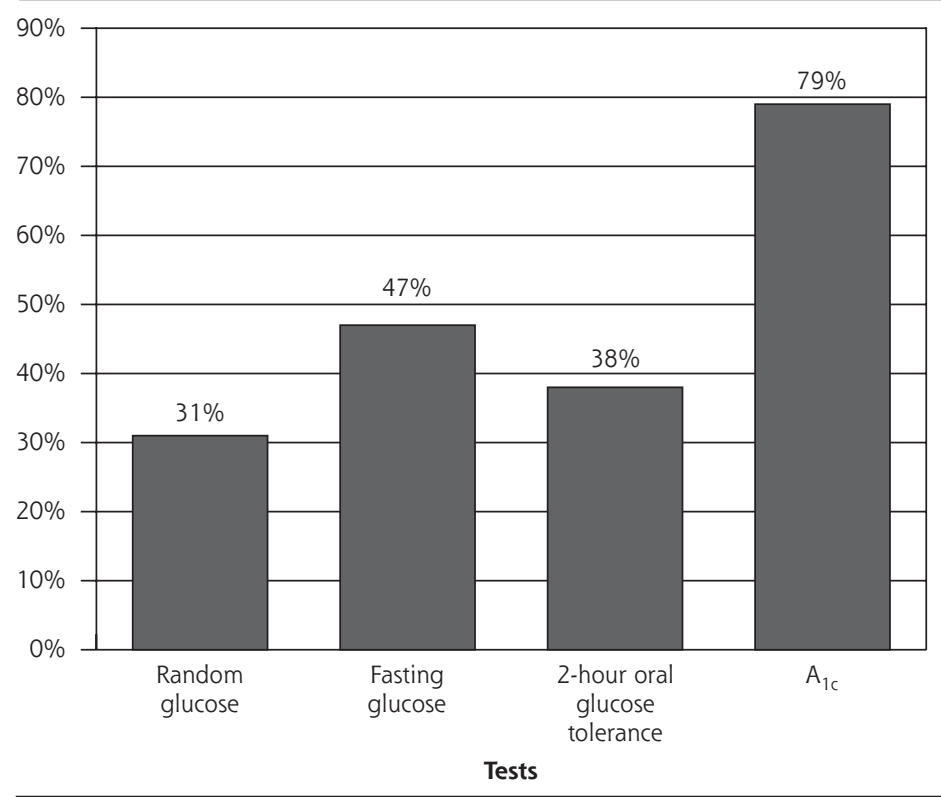

$\mathrm{HbA}_{1 \mathrm{c}}=$ glycated hemoglobin. 


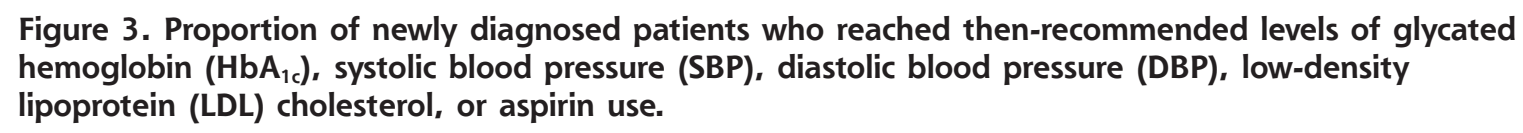

12 months later

At time of diagnosis

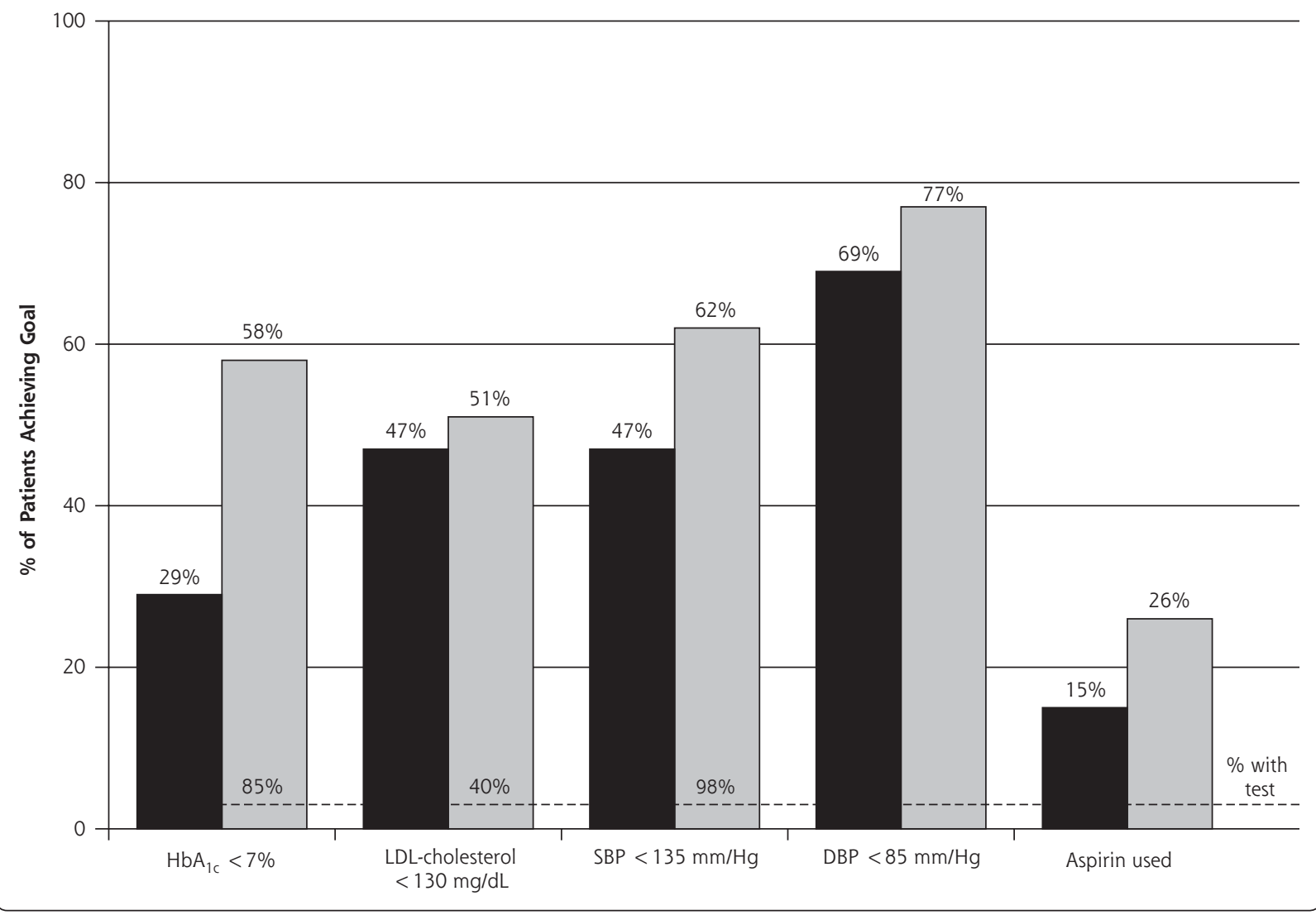

quantified in previous publications. ${ }^{33,34}$ For example, the observed $\mathrm{HbA}_{1 \mathrm{c}}$ change of $-1.8 \%$ over 12 months substantially exceeded the improvement trend of $-0.2 \%$ per year in all adults with diabetes from 1994 to 1996. Similarly, the decrease in systolic and diastolic blood pressures observed over 12 months in patients with newly diagnosed diabetes exceeded the blood pressure reduction achieved over 18 months in other local clinics that were focusing extensive resources on improved blood pressure control. ${ }^{33,35}$ Only small improvements in control of LDL-cholesterol occurred in the study population during the years of the study; more dramatic changes in LDL-cholesterol values have been observed recently. ${ }^{36}$

Our findings extend results of previous studies done in the United Kingdom and the United States that show about $50 \%$ to $80 \%$ of adults with newly diagnosed diabetes have hyperglycemia symptoms that antedate the diagnosis. ${ }^{11,13,15} \mathrm{~A}$ recent qualitative study of adults with newly diagnosed diabetes suggests that patients often do not associate classic diabetes symptoms with the disease and have limited understanding of diabetes before their diagnosis, even when relatives have diabetes. ${ }^{17}$

Other studies have described the characteristics of adults whose diabetes was first diagnosed through systematic office-based screening. ${ }^{13,37,38}$ The overall yield from systematic screening of patients attending clinics is low, fewer men than women accept an invitation to be screened, and those with newly detected diabetes frequently have uncontrolled cardiovascular risk factors. ${ }^{39}$ A small study of 56 Veterans Administration patients with diabetes diagnosed through screening showed no blood pressure improvement and generally ineffective glucose management in the year after diagnosis. ${ }^{18}$ Our findings are quite different $;$ both those with and those without symptoms at diagnosis had significantly improved glucose control and cardiovascular risk factor control within 1 year.

The physicians in this practice used a wide range of tests to diagnose diabetes. Patients with hyperglycemia symptoms were more likely to have a random glucose test, as might be expected on clinical grounds. 
Patients averaged 1.9 glycemia-related tests, and more than $38 \%$ of patients had an oral glucose tolerance test Nearly $80 \%$ had an $\mathrm{HbA}_{1 \mathrm{c}}$ test on or before the date of diabetes diagnosis. Many of these $\mathrm{HbA}_{1 \mathrm{c}}$ tests may have been done for assessment rather than diagnosis, but many physicians believe $\mathrm{HbA}_{1 \mathrm{c}}$ is a useful diagnostic test, in part because it carries important information about prognosis. ${ }^{40}$ Since the study was done, changes in diagnostic criteria and in recommended treatment goals for diabetes have occurred; these changes underscore the importance of aggressive efforts to diagnose diabetes and promptly control risk factors for complications. ${ }^{41}$

Several factors limit the interpretation of these data First, the study population was drawn from a single large medical group. Local demographics and relatively high local levels of diabetes awareness among both patients and physicians may have affected the results. If this is the case, the proportion of patients with newly diagnosed diabetes who are already symptomatic before the diagnosis might be even higher in other settings. Second, the complex web of events leading to diabetes diagnosis is difficult to unravel, and we had no way to classify patient self-diagnosis of diabetes, which has been described in a small proportion of patients in previous studies ${ }^{17}$ i however, we developed an a priori classification system that allowed 504 of the 533 study patients to be classified in a reproducible way by symptoms and type of visit.

Despite these limitations, the data clearly show that for nearly one half the study patients, diagnosis of diabetes was accomplished not by screening asymptomatic patients, but rather by clinical recognition of classic short- and long-term diabetes-related symptoms at visits scheduled for reasons unrelated to diabetes. After diagnosis, patients had significant reductions in $\mathrm{HbA}_{\mathrm{cc}}$ values and other risk factors that could not be attributed to secular trends in diabetes care. Timely diabetes diagnosis is thus likely to have a beneficial impact on patients' future clinical course by decreasing the amount of time they are exposed to high levels of adverse risk factors. ${ }^{16,31,42}$ More aggressive and systematic efforts to diagnose diabetes earlier in its clinical course should be seriously considered as clinical policy.

To read or post commentaries in response to this article, see it online at http://www.annfammed.org/cgi/content/full/4/1/15.

Key words: Diabetes; glycemic control; diagnosis; cardiovascular risk; primary care

Submitted October 20, 2004; submitted, revised, September 6, 2005; accepted September 15, 2005.

Funding support: This study was supported by a contract from the Centers for Disease Control and Prevention to HealthPartners Research Foundation.

\section{References}

1. Harris MI, Flegal KM, Cowie CC, et al. Prevalence of diabetes, impaired fasting glucose, and impaired glucose tolerance in U.S. adults: the Third National Health and Nutrition Examination Survey, 1988-1994. Diabetes Care. 1998;21:518-524.

2. Mokdad AH, Bowman BA, Ford ES, et al. The continuing epidemics of obesity and diabetes in the United States. JAMA. 2001;286:1195-1200.

3. O'Connor PJ, Rush WA, Prochaska JO, Pronk NP, Boyle RG. Professional advice and readiness to change behavioral risk factors among members of a managed care organization. Am J Manag Care. 2001;7:125-130.

4. Centers for Disease Control and Prevention. Prevalence of diabetes and impaired fasting glucose in adults-United States, 1999-2000. MMWR Morb Mortal Wkly Rep. 2003;52:833-837.

5. Engelgau MM, Narayan KM. Finding undiagnosed type 2 diabetes: is it worth the effort? Eff Clin Pract. 2001;4:281-283.

6. Schellhase KG, Koepsell TD, Weiss NS, Wagner EH, Reiber GE. Glucose screening and the risk of complications in type 2 diabetes mellitus. J Clin Epidemiol. 2003;56:75-80.

7. American Diabetes Association. Screening for type 2 diabetes. Diabetes Care. 2004;27(Suppl 1):S11-S14.

8. U.S. Preventive Services Task Force. Screening for type 2 diabetes mellitus in adults: recommendations and rationale. Ann Intern Med. 2003; 138:212-214.

9. Harris R, Donahue K, Rathore SS, et al. Screening adults for type 2 diabetes: a review of the evidence for the U.S. Preventive Services Task Force. Ann Intern Med. 2003;138:215-229.

10. The cost-effectiveness of screening for type 2 diabetes. CDC Diabetes Cost-Effectiveness Study Group, Centers for Disease Control and Prevention. JAMA. 1998;280:1757-1763.

11. Burrows PJ, Gray PJ, Kinmonth $A L$, et al. Who cares for the patient with diabetes? Presentation and follow-up in seven Southampton practices. J R Coll Gen Pract. 1987;37:65-69.

12. Westlund K. Incidence of diabetes mellitus in Oslo, Norway 1925 to 1954. Br J Prev Soc Med. 1966;20:105-116.

13. UK Prospective Diabetes Study. IV. Characteristics of newly presenting type 2 diabetic patients: male preponderance and obesity at different ages. Multi-centre Study. Diabet Med. 1988;5:154-159.

14. UK Prospective Diabetes Study. XII: Differences between Asian, AfroCaribbean and white Caucasian type 2 diabetic patients at diagnosis of diabetes. UK Prospective Diabetes Study Group. Diabet Med. 1994;11:670-677.

15. Singh BM, Jackson DM, Wills R, Davies J, Wise PH. Delayed diagnosis in non-insulin dependent diabetes mellitus. BMJ. 1992;304:11541155.

16. Cathelineau G, de Champvallins M, Bouallouche A, Lesobre B. Management of newly diagnosed non-insulin-dependent diabetes mellitus in the primary care setting: effects of 2 years of gliclazide treatment-the Diadem Study. Metabolism. 1997;46:31-34.

17. Koopman RJ, Mainous AG 3rd, Jeffcoat AS. Moving from undiagnosed to diagnosed diabetes: the patient's perspective. Fam Med. 2004;36:727-732.

18. Edelman D, Olsen MK, Dudley TK, Harris AC, Oddone EZ. Quality of care for patients diagnosed with diabetes at screening. Diabetes Care. 2003;26:367-371.

19. Haffner SM, Lehto S, Ronnemaa T, Pyorala K, Laakso M. Mortality from coronary heart disease in subjects with type 2 diabetes and in nondiabetic subjects with and without prior myocardial infarction. $N$ Engl J Med. 1998;339:229-234.

20. O'Connor PJ, Rush WA, Rardin KA, Isham G. Are HMO members willing to engage in two-way communication to improve health? HMO Pract. 1996;10:17-19. 
21. O'Connor PJ, Rush WA, Pronk NP, Cherney LM. Identifying diabetes mellitus or heart disease among health maintenance organization members: sensitivity, specificity, predictive value, and cost of survey and database methods. Am J Manag Care. 1998;4:335-342.

22. Classification and diagnosis of diabetes mellitus and other categories of glucose intolerance. National Diabetes Data Group. Diabetes. 1979;28:1039-1057.

23. Huisman $\mathrm{TH}$, Henson JB, Wilson JB. A new high-performance liquid chromatographic procedure to quantitate hemoglobin $\mathrm{A} 1 \mathrm{C}$ and other minor hemoglobins in blood of normal, diabetic, and alcoholic individuals. J Lab Clin Med. 1983;102:163-173.

24. Rush WA. Does a modified Charlson Comorbidity Score predict mortality in a health plan population? Paper presented at: Minnesota Health Services Research Conference, 2001, Minneapolis, Minn.

25. Deyo RA, Cherkin DC, Ciol MA. Adapting a clinical comorbidity index for use with ICD-9-CM administrative databases. J Clin Epidemiol. 1992;45:613-619.

26. Kieszak SM, Flanders WD, Kosinski AS, Shipp CC, Karp H. A comparison of the Charlson Comorbidity Index derived from medical record data and administrative billing data. J Clin Epidemiol. 1999;52:137-142.

27. SAS [computer program]. Version 8.02. Cary, NC: SAS Institute, Inc; 1999-2001.

28. Health Care Guidelines; 1994-1995. Bloomington, Minn: Institute for Clinical Systems Integration (ICSI); 1995.

29. Intensive blood-glucose control with sulphonylureas or insulin compared with conventional treatment and risk of complications in patients with type 2 diabetes (UKPDS 33). UK Prospective Diabetes Study (UKPDS) Group. Lancet. 1998;352:837-853.

30. Effect of intensive blood-glucose control with metformin on complications in overweight patients with type 2 diabetes (UKPDS 34). UK Prospective Diabetes Study (UKPDS) Group. Lancet. 1998;352:854865.

31. Sutton-Tyrrell K, Wildman R, Newman A, Kuller LH. Extent of cardiovascular risk reduction associated with treatment of isolated systolic hypertension. Arch Intern Med. 2003;163:2728-2731.
32. Writing Team for the Diabetes Control and Complications Trial/Epidemiology of Diabetes Interventions and Complications Research Group. Sustained effect of intensive treatment of type 1 diabetes mellitus on development and progression of diabetic nephropathy: the Epidemiology of Diabetes Interventions and Complications (EDIC) study. JAMA. 2003;290:2159-2167.

33. O'Connor PJ, Quiter ES, Rush WA, et al. Impact of hypertension guideline implementation on blood pressure control and drug use in primary care clinics. Jt Comm J Qual Improv. 1999;25:68-77.

34. Sperl-Hillen J, O'Connor PJ, Carlson RR, et al. Improving diabetes care in a large health care system: an enhanced primary care approach. Jt Comm J Qual Improv. 2000;26:615-622.

35. Angstman GL. Disease management strategy. Managing quality and care: hypertension. Paper presented at: Spring Refresher Proceedings, Minnesota Academy of Family Physicians, 1997, Minneapolis, Minn.

36. Sperl-Hillen JM, O'Connor PJ. Factors driving diabetes care improvement in a large medical group: ten years of progress. Am J Manag Care. 2005;11:S177-S185.

37. O'Connor PJ, Rush WA, Cherney LM, Pronk NP. Screening for diabetes mellitus in high-risk patients: cost, yield, and acceptability. Eff Clin Pract. 2001;4:271-277.

38. Lawrence JM, Bennett P, Young A, Robinson AM. Screening for diabetes in general practice: cross sectional population study. BMJ. 2001;323:548-551

39. Hu FB, Stampfer MJ, Haffner SM, et al. Elevated risk of cardiovascular disease prior to clinical diagnosis of type 2 diabetes. Diabetes Care. 2002;25:1129-1134

40. Peters AL, Davidson MB, Schriger DL, Hasselblad V. A clinical approach for the diagnosis of diabetes mellitus: an analysis using glycosylated hemoglobin levels. Meta-analysis Research Group on the Diagnosis of Diabetes Using Glycated Hemoglobin Levels. JAMA. 1996;276:1246-1252.

41. Report of the Expert Committee on the Diagnosis and Classification of Diabetes Mellitus. Diabetes Care. 1997;20:1183-1197.

42. Hillson RM, Hockaday TD, Newton DJ, Pim B. Delayed diagnosis of non-insulin-dependent diabetes is associated with greater metabolic and clinical abnormality. Diabet Med. 1985;2:383-386. 